\title{
A Co-Delivery Strategy of Abemaciclib Combined with Vitamin E Succinate Based on Hyaluronic Acid Modified Calcium Phosphate to Enhance the Anti- Cancer Effect
}

\author{
Yuanyuan Liu \\ Sichuan University \\ $\mathrm{Na}$ Gan \\ Sichuan University \\ Shuangshuang Zhang \\ Sichuan University \\ Qiaomei Sun \\ Sichuan University \\ Xin Wei \\ Sichuan University \\ Xiuyun Ren \\ Sichuan University \\ Xi Xiang \\ Sichuan University \\ Hui Li ( $\square$ lihuilab@sina.com ) \\ Sichuan University
}

\section{Research Article}

Keywords: Calcium phosphate, Hyaluronic acid, Drug co-delivery, Abemaciclib

Posted Date: July 20th, 2021

DOI: https://doi.org/10.21203/rs.3.rs-729230/v1

License: (c) (i) This work is licensed under a Creative Commons Attribution 4.0 International License. Read Full License 


\section{Abstract}

Combination therapy including anticancer drugs usually induces synergistic effects, especially in combination with natural compounds as a chemical sensitizer. Nano-based drug delivery technology is also effective in solving the toxicity of single drugs at high doses. In this study, we established a codelivery strategy for abemaciclib (ABE) combined with vitamin E succinate (VES) based on HA-modified calcium phosphate ( $\mathrm{CaP}$ ) nanomaterials to enhance anti-cancer effect. The nano-sized HA/CaP particles $(90 \mathrm{~nm})$ have a hollow structure. Surprisingly, after modification with $\mathrm{HA}, \mathrm{HA} / \mathrm{CaP}$ has more $\mathrm{pH}$ sensitivity. CaP released $30 \% \mathrm{ABE}$ and $91 \%$ VES at $\mathrm{pH} 7.4$, whereas $\mathrm{HA} / \mathrm{CaP}$ vsreleased $14 \% \mathrm{ABE}$ and $32 \%$ VES at the same $\mathrm{pH}$. Cell experiments showed that $\mathrm{HA} / \mathrm{CaP} / \mathrm{ABE}-\mathrm{VES}$ had stronger cell inhibitory effect on MCF-7 compared with CaP/ABE-VES. This inorganic/organic composite for the co-delivery of ABE and VES has obvious tumor inhibition effect, and is ideal for anti-tumor drug delivery.

\section{Introduction}

CDK 4/6 inhibitor abemaciclib (ABE) plays a central role in tumor formation, and has become an important molecular target drug for the clinical treatment of breast cancer[1]. However, clinical data shows that the objective remission rate of $A B E$ is only $19.7 \%[2]$. The anti-tumor effect of ABE still needs to be improved by other strategies, such as combination therapy. A variety of cyclin D-related signaling pathways (like estrogen epidermal growth factor receptor, phosphoinositide 3-kinase and NF-kB) have great potential in combination with $A B E[3,4]$. The natural derivative of vitamin $E$, vitamin $E$ succinate (VES), has attracted people's attention because of its synergistic anticancer activity $[5,6]$. VES has been reported to induce apoptosis of cancer cells by inhibiting the NF-KB[7, 8]. The combination of ABE and VES has synergistic potential in the treatment of breast cancer.

Moreover, multimodal cancer therapy, which combines chemotherapy and multifunctional nanomaterials, has remarkably improved the efficacy of cancer therapy and may provide a better solution to overcome the poor efficacy of single chemotherapeutic agents $[9,10]$. Calcium phosphate (CaP)-based nanocarrier materials $\mathrm{pH}$ responsiveness as they can decompose under acidic conditions; thus, they have a wide range of applications in the field of biological medicine, including transfection, gene silencing, drug delivery, and biological imaging[11, 12]. The incorporation of Hyaluronic acid (HA) can make nanoparticles (NPs) specifically bind to the CD44 receptor on the surface of CD44-overexpressed tumor cell. The HA layer also could improve the stability of the nanocomposite, which significantly enhance cellular uptake[13,14]. Based on this foundation, Xiong and colleagues reported HA-modified NPs with high drug loading efficiency and $\mathrm{pH}$-responsive drug release[15]. Min and colleagues prepared 3, 4dihydroxy-L-phenylalanine-coupled HA-stabilized CaP NP for the targeted delivery of siRNA to tumor sites[16]. This gene delivery platform shows great potential for siRNA delivery and targeted cancer therapy. But most of the researches on $\mathrm{CaP}$ and $\mathrm{HA}$ are focus on gene drug delivery and stagnate in single-drug delivery[17, 18]. As a widely studied drug carrier, $\mathrm{CaP}$ and $\mathrm{HA}$ still have potential for further application in drug co-delivery. More effective strategies for the treatment breast cancer need to be 
developed to solve the poor effect of $A B E$ and improve the benefits of anticancer therapies without attendant toxicity.

We expect that the HA/CaP system can load two drugs at the same time, which could fully use dual drug synergy and nano-carrier drug delivery system. With this idea in mind, this study designed a HA-coated and CaP-based drug delivery system for the controlled release of $A B E$ and VES, to achieve the effective controlled drug release of nano-carrier and a synergistic anti-cancer effect for breast cancer.

\section{Materials And Method \\ 2.1 Materials}

Abemaciclib ( $F W=506.59$, purity $\geq 98 \%$ ) was purchased from Shanghai Topbiochem Technology Co. Ltd. (Shanghai, China), vitamin E succinate $(F W=530.78$, purity $\geq 98 \%)$ and sodium hyaluronate ( $F W$ : $100-$ $200 \mathrm{kDa}$ ) were attained from Heowns (Tianjin, China). $\mathrm{NaOH}$, phosphate buffer solution (PBS), disodium hydrogen phosphate, calcium chloride, hydrochloric acid, methanol, acetic acid, and ammonium acetate were obtained from Ke-Long Chemical Reagent Factory (Chengdu, China). Purified water was used throughout the experiment. All of the reagents and chemicals used in this study were of analytical or chromatographic grade and used without further purification.

\subsection{Preparation of $\mathrm{CaP}$ and $\mathrm{HA} / \mathrm{CaP} \mathrm{NPs}$}

Cetyltrimethylammonium bromide (CTAB) was dissolved in $50 \mathrm{~mL}$ of water to a concentration of $1 \mathrm{mM}$. The solution was stirred for $10 \mathrm{~min}$ at $500 \mathrm{rpm}$ (room temperature) to obtain the CTAB micelle. The mineralized micelles were prepared by the classical chemical precipitation method according to previous literature reports $[19,20]$. The details are as follows: $\mathrm{Na}_{2} \mathrm{HPO}_{4}(2 \mathrm{~mL}, 60 \mathrm{mM})$ was added drop dropwise into the solution containing CTAB micelles at $500 \mathrm{rpm}$ and $45^{\circ} \mathrm{C}$ After $0.5 \mathrm{~h}, 2 \mathrm{~mL}$ of $100 \mathrm{mM} \mathrm{CaCl}_{2}$ was added into a $50 \mathrm{~mL}$ solution containing $1.2 \mathrm{mM} \mathrm{Na}_{2} \mathrm{HPO}_{4}$ and $1 \mathrm{mM} \mathrm{CTAB}$ under magnetic stirring $(\mathrm{pH}=$ 10.0 , $\mathrm{pH}$ was adjusted by $0.1 \mathrm{M}$ ammonia solution) for $1 \mathrm{~h}$. The temperature was kept at $45^{\circ} \mathrm{C}$ by water bath. The suspension was aged at room temperature for $3 \mathrm{~h}$, and the precipitate was washed with purified water three times. CaP product was obtained after $24 \mathrm{~h}$ of freeze-drying. The "one-pot " method was used to prepare HA/CaP NPs. Sodium hyaluronate solution $(2 \%, \mathrm{~m} / \mathrm{v})$ was added dropwise to the $\mathrm{CaP}$ nanosphere suspension. The suspension was aged at room temperature for $3 \mathrm{~h}$. The precipitate was washed three times with purified water and freeze-dried for $24 \mathrm{~h}$ to obtain the HA/CaP product.

\subsection{Drug encapsulation experiment}

$A B E$ and VES were dissolved in ethanol then to CTAB micellar solution to obtain CaP/ABE-VES and $\mathrm{HA} / \mathrm{CAP} / \mathrm{ABE}-\mathrm{VES}$. The quantification of dual-drug was determined by high performance liquid chromatography (Agilent 1200, USA). Before that, we tested the effect of blank carrier on drug absorption using ultraviolet-visible spectrophotometry (Shimadzu, Japan). The detailed measurement of drug content is as follows: NPs were dissolved in $0.1 \mathrm{M}$ hydrochloric acid, dilute with methanol, and 
ultrasonicated for 10 min to destroy the structure of CaP/ABE-VES and HA/CaP/ABE-VES. After cooling to room temperature, the NPs were filtered with $0.22 \mu \mathrm{m}$ micropores. Retention time and peak area were recorded, and the contents of ABE and VES were calculated at 296 and $284 \mathrm{~nm}$ according to the regression equation. The formulas for calculating the drug loading rate $(\mathrm{DL})$ and encapsulation efficiency $(\mathrm{EE})$ are as follows:

$$
\begin{gathered}
\mathrm{DL} \%=\frac{\text { Weight of drug in nanoparticles }}{\text { Total weight of drug loaded nanoparticles }} \\
\times 100 \%
\end{gathered}
$$

$$
\mathrm{EE} \%=\frac{\text { Weight of drug in nanoparticles }}{\text { Weight of feeding drug }} \times 100 \%
$$

\subsection{Characterization of CaP and HA/CaP NPs}

Nicolet 6700 Fourier infrared spectrometer (Thermo Fisher Technology Co., Ltd., USA) was used to test the prepared $\mathrm{CaP}, \mathrm{HA} / \mathrm{CaP}, \mathrm{CaP} / \mathrm{ABE}-\mathrm{VES}, \mathrm{HA} / \mathrm{CaP} / \mathrm{ABE}-\mathrm{VES}$, physical mixture (PM) and active pharmaceutical ingredient (API) by $\mathrm{KBr}$ tablet method. The samples to be tested consist of $100 \mathrm{mg} \mathrm{KBr}$ and $1 \mathrm{mg}$ sample. The sample mixture was pressed into a sheet of about $1 \mathrm{~mm}$, the wavenumber was set between 4000 and $400 \mathrm{~cm}^{-1}$, the resolution is $4 \mathrm{~cm}^{-1}$, and the number of scans was 64 times.

The degrees of crystallinity were measured by X'Pert PRO diffractometer (PANalytical, Netherlands). The test conditions were as follows: $\mathrm{Cu}$ Ka radiation, tube voltage was $40 \mathrm{kV}$, tube current was $40 \mathrm{~mA}, 2 \theta$ range was set between 5 and $50^{\circ}$, anti-scatter slit was $1 / 4^{\circ}$, scattering slit was $1 / 8^{\circ}$, step size was $0.01313^{\circ}(2 \theta)$, and counting time was $30 \mathrm{~ms} / \mathrm{step}$.

A JSM-7500F scanning electron microscope (Olympus, Japan) and a JEM-2100 Plus transmission electron microscope (JEOL, Japan) were used to observe the morphology of the prepared CaP and HA/CaP NPs. The NPs for TEM characterization were dispersed in the aqueous solution, dropped onto a copper mesh covered with a carbon film, air-dried, and placed in a detector for observation. The INCA XMax50 energy spectrometer equipped with SEM system was used for semi-quantitative elemental analysis of $\mathrm{CaP}, \mathrm{HA} / \mathrm{CaP}, \mathrm{CaP} / \mathrm{ABE}-\mathrm{VES}$ and HA/CaP/ABE-VES.

The prepared $\mathrm{CaP}$ and $\mathrm{HA} / \mathrm{CaP}$ NPs were tested for hydrodynamic diameter and zeta potential using ZEN3690 nanoparticle size potential analyzer (Malvern, UK) at $25^{\circ} \mathrm{C}$. The sample was dispersed in purified water at a concentration of $0.1 \mathrm{mg} / \mathrm{mL}$.

An automatic surface area and porosity analyzer (3H-2000PS2, Beishiide) was used to measure the $\mathrm{N}_{2}$ adsorption-desorption isotherm at $293.15 \mathrm{~K}$. The Brunauer-Emmett-Teller (BET) method was used to calculate the specific surface area at a relative pressure ranging from 0.05 to 0.95 . Pore volume and pore size distribution were obtained from the desorption curve of the isotherm using the Barrett-JoynerHalanda (BJH) method. 
Thermal analysis was performed on the TG 209F1 Iris thermogravimetric analyzer (NETZSCH, Germany) with a heating rate of $10^{\circ} \mathrm{C} / \mathrm{min}$, a temperature setting range of $30-600^{\circ} \mathrm{C}$, and a nitrogen flow of 60 $\mathrm{mL} / \mathrm{min}$.

\subsection{In vitro drug release}

Drug release performance is one of the criteria whether a drug carrier can be practicallt used[21]. The tumor microenvironment is weakly acidic, at a $\mathrm{pH}$ range within $4.5-6.5$, whereas the $\mathrm{pH}$ of the blood is about 7.4. We uses PBS with different $\mathrm{pH}$ values $(\mathrm{pH}=4.5,7.4)$ to simulate drug release in tumor and normal tissues for $8 \mathrm{~h}$ and calculated the cumulative release rates of the two drugs.

PBS containing $0.2 \mathrm{~mol} / \mathrm{L} \mathrm{KH}_{2} \mathrm{PO}_{4}$ with $\mathrm{pH}=4.5$ was prepared, and PBS with $\mathrm{pH}=7.4$ was obtained by adjusting the $\mathrm{pH}$ with $0.2 \mathrm{M} \mathrm{NaOH}$. In order to increase the dissolution of poorly soluble drugs, $0.1 \%$ Tween 80 was added to the PBS to obtain the required dissolution medium. The drug dissolution experiment was carried out in a constant temperature shaker at $37^{\circ} \mathrm{C}$ and $200 \mathrm{rpm}$. Samples $(1 \mathrm{~mL})$ were pipetted at $5 \mathrm{~min}, 10 \mathrm{~min}, 1 \mathrm{~h}, 4 \mathrm{~h}$, and $8 \mathrm{~h}$ for test and $1 \mathrm{~mL}$ of fresh dissolution medium at the same temperature was added to maintain the total volume of the release medium unchanged. The taken-out solution was filtered through a $0.22 \mu \mathrm{m}$ microporous membrane. Cumulative release rate $R(\%)$ was calculated. Each experiment was done in parallel three times, and take the average value.

$$
R(\%)=\frac{C_{n} \times V_{0}+V_{i} \sum_{i=1}^{n-1} C_{i}}{m} \times 100 \%
$$

where: $C_{n}$ is the drug concentration of the sample to be tested for the $\mathrm{n}$-th time $(\mathrm{mg} / \mathrm{mL}) ; C_{i}$ is the drug concentration of the dissolution medium at the $i$-th sampling; $V_{0}$ is the total volume of the release medium $(\mathrm{mL}) ; V_{i}$ is the sampling volume; $m$ is the total mass $(\mathrm{mg})$ of the drug contained in the sample.

\subsection{In vitro cytotoxicity}

Cell counting kit 8 (CCK8) assay was used to measure cell viability. Briefly, 293T and MCF-7 cells were added in the 96 -well plates at $37^{\circ} \mathrm{C}$ with $5 \% \mathrm{CO}_{2}$ for $24 \mathrm{~h}$. Free ABE and VES $(100 \mu \mathrm{L})$ in Dulbecco's modified Eagle medium (DMEM) and cell culture medium containing gradient concentrations of carriers either with or without drug $(6.25-200 \mu \mathrm{g} / \mathrm{mL})$ were added to these cells after removing the old medium. After $48 \mathrm{~h}, 10 \mu \mathrm{L}$ of CCK8 solution was added to each well, incubated for $2 \mathrm{~h}$, and placed in a microplate reader (SoftMax Pro 7.1) to measure the optical density value at $450 \mathrm{~nm}$. Cell inhibition rate was calculated, and IBM SPSS Statistics 24 software was used to calculate the half maximal inhibitory concentration $\left(\mathrm{IC}_{50}\right)$. The formula for calculating cell inhibition rate is as follows:

Cell inhibition rate $(\%)=\left(1-\frac{\text { Experimental group }- \text { Control group }}{\text { Negative control group }- \text { Control group }}\right) \times 100 \%$

\section{Results And Discussion}




\subsection{Preparation of blank and drug-loaded NPs}

The UV spectra of ABE, VES, CaP and HA are shown in Fig. 1. CaP and HA/CaP have no UV absorption in the range of $250-400 \mathrm{~nm}$, indicating that blank carriers will not interfere with the content determination of $A B E$ and $V E S$. The quantitative results showed that the drug loading rates and encapsulation rate of $A B E$ in the CaP/ABE-VES system were $4.02 \%$ and $20.11 \%$, respectively, whereas those of VES were $14 \%$ and $69.54 \%$, respectively. The drug loading rate and encapsulation rate of ABE in the HA/CaP/ABE-VES system were $3.65 \%$ and $18.24 \%$, respectively, whereas those of VES were $16 \%$ and $78.79 \%$, respectively. The drug-loading effects of both systems were better on VES than ABE. This outcome may be helpful because VES is harmless to normal cells as a chemical sensitizer; thus, it could reduce the dosage of ABE and increase anti-cancer activity. This conclusion is verified in the results of subsequent cell viability experiments.

\subsection{Shape, particle size, and zeta potential}

CTAB micelles further formed to to CaP nanospheres with multivesicular structure and a particle size of about $80 \mathrm{~nm}$ under the deposition and mineralization of phosphate and calcium salt (Fig. 2A). The particle size of $\mathrm{HA} / \mathrm{CaP}$ increased to $90 \mathrm{~nm}$ because of the presence of a $10 \mathrm{~nm}$ HA shell (Fig. 2B). The SEM results show that $\mathrm{CaP}$ has a nano-sized spherical structure and uniform overall morphology. $\mathrm{HA} / \mathrm{CaP}$ is denser under SEM. This is because the negative charge carried by HA neutralizes the positive charge on the surface of $\mathrm{CaP}$, which weakens the repulsive force against agglomeration on the surface of NPs. Particle size distribution curve (Figs. 2C and 2D) shows that the average hydrodynamic diameter of $\mathrm{CaP}$ and $\mathrm{HA} / \mathrm{CaP}$ measured by dynamic light scattering (DLS) is about $100 \mathrm{~nm}$ and $110 \mathrm{~nm}$. The particle size of the sample measured by the electron microscope is smaller than the value measured by the DLS due to the shrinkage and the reduction during the external force of air drying. As shown in Fig. 2D, zeta potential measurement shows that the surface charge of $\mathrm{CaP}$ is about $9.4 \pm 0.80 \mathrm{mV}$, this indicates the

presence of $\mathrm{Ca}^{2+}$ on $\mathrm{CaP}$ surface. The surface potential of $\mathrm{HA} / \mathrm{CaP}$ decreased to $-4.3 \pm 0.25 \mathrm{mV}$, indicating that $\mathrm{Ca}^{2+}$ on the surface of $\mathrm{CaP}$ changed into carboxyl anion after $\mathrm{HA}$ covered on it, which confirmed that $\mathrm{HA}$ was successfully coated on the surface of $\mathrm{CaP}$. Above results show that $\mathrm{CaP}$ with a spherical hollow structure was successfully prepared and $\mathrm{HA}$ coats on the surface of $\mathrm{CaP}$ under electrostatic interaction.

\subsection{Infrared analysis}

Figures $3 \mathrm{~A}$ and $3 \mathrm{~B}$ shows the infrared spectra of blank and drug-loaded $\mathrm{CaP}$ and $\mathrm{HA} / \mathrm{CaP}$. The absorption at $1036 \mathrm{~cm}^{-1}$ is attributed to the stretching vibration of the P-O bond. The characteristic absorption at $604 \mathrm{~cm}^{-1}$ and $566 \mathrm{~cm}^{-1}$ is caused by the bending vibration of O-P-O. This indicates that CaP with a hydroxyapatite structure was successfully prepared[22]. The absorption peaks of HA at $3423 \mathrm{~cm}^{-1}, 2923$ $\mathrm{cm}^{-1}$, and $1044 \mathrm{~cm}^{-1}$ correspond to the stretching vibrations of its carboxyl, methylene and $\mathrm{C}-0$ groups, respectively. Compared with $\mathrm{CaP}$, the absorption of $\mathrm{HA} / \mathrm{CaP}$ at $2923 \mathrm{~cm}^{-1}$ is enhanced, as a result of the presence of increased methylene groups in the HA molecule. Infrared spectroscopy analysis also 
confirmed the presence of $A B E$ and VES in drug carriers. The absorption band in the wavenumber range of $1400-1600 \mathrm{~cm}^{-1}$ is caused by the benzene ring vibration of $A B E$, and the double peaks in the spectrum of PM at $1715 \mathrm{~cm}-1$ and $1753 \mathrm{~cm}-1$ correspond to the carbonyl absorption of ester and carboxyl groups in VES. Those peaks appears in PM, but disappears in CaP/ABE-VES and HA/CaP/ABEVES, this phenomenon may be due to the in-situ loading effect of the nanomaterials on the drug, which makes the drug molecules doped inside the material and causes peaks to weaken or disappear. The infrared results confirm that the prepared $\mathrm{CaP}$ is a calcium-deficient hydroxyapatite, and the drugs are encapsulated in the nanomaterials because of the in-situ drug-loading effect.

\subsection{Crystallinity and element analysis}

All of synthesized products showed hydroxyapatite-like characteristics in X-ray diffraction (XRD) analysis. $\mathrm{CaP}$ has two characteristic peaks at $26^{\circ}$ and $32^{\circ}$. It can be indexed as a calcium-deficient hydroxyapatite structure with poor crystallinity[23]. The poor crystallinity is attributed to the low reaction temperature $\left(40^{\circ} \mathrm{C}\right)$, which is consistent with reported literature, that is, CaP particles synthesized at low temperatures often show low crystallinity, high solubility and large specific surface area[24]. This result is conducive because a study on the resorption of biomaterials for hard tissue treatment showed that low-crystalline $\mathrm{CaP}$ is more degradable than $\mathrm{CaP}$ synthesized by sintering or other methods[25]. Therefore, the synthesized calcium-deficient CaP nanomaterials may have better biocompatibility. Figures $3 \mathrm{C}$ and $3 \mathrm{D}$ indicates that the drug is not simply mixed after being loaded in situ by $\mathrm{CaP}$ and $\mathrm{HA} / \mathrm{CaP}$. This result was consistent with the infrared result. The characteristic diffraction peak of HA/CaP/ABE-VES at $26^{\circ}$ is weaker than that of blank HA/CaP. This may be due to the hydrogen bond between $\mathrm{HA}$ and the two drugs. The hydrogen bonding between the drug and the carrier resulted in lower crystallinity[26]. Energydispersive X-ray spectroscopy analysis showed a $1.5 \mathrm{Ca} / \mathrm{P}$ ratio, which further indicates that the synthesized $\mathrm{CaP}$ is a kind of calcium-deficient hydroxyapatite with poor crystallinity[27]. The $\mathrm{C}, \mathrm{O}$, and $\mathrm{F}$ elements in $\mathrm{HA} / \mathrm{CaP} / \mathrm{ABE}-\mathrm{VES}$ also increased, indicating that the incorporation of $\mathrm{HA}$ can increase the drug loading of nanomaterials (Fig. S1).

\subsection{Specific surface area and pore size distribution}

As shown in Figs. 3E and 3F, the surface area of the CaP nanospheres is $123.90 \mathrm{~m}^{2} \mathrm{~g}^{-1}$. CaP has a large specific surface area, which is beneficial to the adsorption and loading of small molecule drugs. The surface area of CaP decreased to $89.94 \mathrm{~m}^{2} \mathrm{~g}^{-1}$ after coating with HA, because some mesoporous channels were covered by HA, resulting in a decrease in specific surface area. This phenomenon has also been found in previous literature[28]. $\mathrm{N}_{2}$ adsorption curve of CaP shows that it has an obvious mesoporous structure. Figure 3 shows that the pore size of CaP is approximately $31.78 \mathrm{~nm}$. The pore size distribution of $\mathrm{HA} / \mathrm{CaP}$ is more uniform. After the addition of $\mathrm{HA}$, pore size and pore volume were reduced to $29.74 \mathrm{~nm}$ and $0.67 \mathrm{~cm}^{3} \mathrm{~g}^{-1}$, respectively. This decrease may be because the incorporation of negatively charged HA makes the internal electrostatic force of mesoporous $\mathrm{HA} / \mathrm{CaP}$ stronger, which results in a more compact structure. This result is consistent with the conclusion of SEM.

\subsection{Thermogravimetric (TG) analysis}


The thermal decomposition is shown in Fig. 4. The endothermic peak of $A B E$ and VES appeared at $360^{\circ} \mathrm{C}$ and $306^{\circ} \mathrm{C}$, respectively. In the range of $150-350^{\circ} \mathrm{C}$, CaP shows a weight loss of $4.04 \%$ at $333^{\circ} \mathrm{C}$, which is attributed to the decomposition of the CaP framework[29]. The derivative thermogravimetric (DTG) curve of CaP/ABE-VES shows that the endothermic peak at $150-350^{\circ} \mathrm{C}$ becomes larger and the weight loss is $11.02 \%$. This result is because of the overlap in the endothermic peaks of VES and CaP in this temperature range. A weight loss of $2.26 \%$ appears at $406^{\circ} \mathrm{C}$, which corresponds to the endothermic peak of $\mathrm{ABE}$ in $\mathrm{CaP} / \mathrm{ABE}-\mathrm{VES}$. The curve of $\mathrm{HA} / \mathrm{CaP} / \mathrm{ABE}-\mathrm{VES}$ shows that the mass loss in this range is $26.59 \%$, which is higher than that of CaP/ABE-VES. These results indicate that the HA/CaP system has a higher drug loading capacity for VES than a single CaP system. The higher drug loading capacity of $\mathrm{HA} / \mathrm{CaP}$ may be due to the COO- group contained in the outer $\mathrm{HA}$, which can provide more binding sites and space for drug molecules. The drug molecule may bind to the $\mathrm{C}$ site of $\mathrm{CaP}$ through electrostatic force, or be incorporated into the amorphous region of $\mathrm{CaP}$ through the $\mathrm{Ca}$ bridge action of the $\mathrm{P}$ site[30]. The thermal decomposition temperature of loaded drugs is higher compared with free drugs. This result also shows that the prepared $\mathrm{HA} / \mathrm{CaP}$ can improve the thermal stability of the loaded drug.

\section{7 pH Sensitivity of CaP and HA/CaP NPs}

The drug release kinetics of $\mathrm{CaP}$ may be controlled by acid-assisted dissolution [31]. In pH 7.4, about $30 \%$ of $A B E$ was released from CaP/ABE-VES after $8 \mathrm{~h}$, which is higher than the $16 \%$ release of a single drug. When the pH dropped to 4.5, the cumulative release of ABE from CaP/ABE-VES can increased to $98 \%$ after $8 \mathrm{~h}$ but the release of a single drug at $\mathrm{pH} 4.5$ is only $60 \%$. In general, CaP makes the release of $A B E$ more complete at $\mathrm{pH}$ 4.5. About $90 \%$ of VES was released from CaP/ABE-VES in $8 \mathrm{~h}$ at $\mathrm{pH} 7.4$, which is similar to the $80 \%$ release of a single drug. The increased release of VES at pH 7.4 is due to the fact that VES is a weakly acidic molecule, and alkaline condition can increase its solubility. When the $\mathrm{pH}$ dropped to 4.5 , the cumulative release of VES from CaP/ABE-VES can reach $100 \%$ after $8 \mathrm{~h}$, whereas only $18 \%$ of the single drug was released. Therefore, the $\mathrm{pH}$ sensitivity of $\mathrm{CaP}$ as a carrier is weak for the controlled release of VES, that is, drug release can be achieved regardless of $\mathrm{pH}$ (4.5 or 7.4). Compared with the CaP system, the $\mathrm{HA} / \mathrm{CaP}$ system released less drugs under acidic conditions. Whereas $\mathrm{HA} / \mathrm{CaP}$ released only $14 \% \mathrm{ABE}$ and $32 \% \mathrm{VES}$ at $\mathrm{pH} 7.4$. This may be because the covering effect of the HA layer prevents the dissolution of the drug. It is surprising that the incorporation of the HA layer greatly reduced the release of $\mathrm{ABE}$ and $\mathrm{VES}$ at $\mathrm{pH} 7.4$, that is, the HA/CaP/ABE-VES system has stronger $\mathrm{pH}$ responsiveness, can release both drugs at $\mathrm{pH} 4.5$, but few released at $\mathrm{pH}$ 7.4. Such release characteristics may weaken the damage of the drug to normal human cells, while killing cancer cells.

\subsection{In vitro cytotoxicity evaluation of $\mathrm{CaP}$ and $\mathrm{HA} / \mathrm{CaP}$ nanomaterials}

The toxicity of the nanocarriers to normal cells and cancer cells were significantly different (Fig. 6(a) and Fig. $6(\mathrm{~b})$ ). When the concentration of $\mathrm{CaP}$ and $\mathrm{HA} / \mathrm{CaP}$ was greater than $50 \mu \mathrm{g} / \mathrm{mL}$, the proliferation of MCF-7 was significantly inhibited. Even the concentration reached up to $200 \mu \mathrm{g} / \mathrm{mL}$, the viability of $293 \mathrm{~T}$ 
cells was above $90 \%(p<0.001)$. The results indicate that the prepared nanomaterials are more damaging to cancer cells, other than normal cells, this is because the increase in calcium ions in the acidic environment of the tumor results in cell death[32].

VES can inhibit the proliferation of a variety of cancer cell, including human neuroblastoma cells, prostate cancer cells, promyelocytic cells, and breast cancer cells but is non-toxic to normal cell lines[33]. The experimental results on the cytotoxicity of VES are consistent with these reports. In vitro cytotoxicity of VES on 293T and MCF-7 cells are shown in Fig. 6(c). VES had no significant inhibitory effect on 293T cells at concentrations up to $200 \mu \mathrm{M}$. By contrast, MCF-7 cells was significantly inhibited at the VES concentration of $50 \mu \mathrm{M}(\mathrm{p}<0.05)$.

The stronger inhibitory effect on MCF-7 may be due to the synergistic effect of the two drugs, which strengthened the anti-tumor effect (Fig. 7(b) and Fig. 7(d)). HA/CaP still retained the $\mathrm{Ca}^{2+}{ }^{2}$-mediated inhibition of cancer cell proliferation after the dissolution of $\mathrm{CaP}$ in the acidic environment of the tumor. On this basis, the surface coating of the HA layer might have further increased the endocytosis of $\mathrm{HA} / \mathrm{CaP}$ at low concentration, to enhance the inhibition of tumor cells at low concentration and consequently reduce the damage to normal cells. The results indicated that the prepared HA/CaP/ABEVES utilizes unique $\mathrm{pH}$ responsiveness to effectively control the release of the drugs. This result is consistent with the results of the in vitro release experiment described in the previous section. The incorporation of HA endows HA/CaP/ABE-VES with stronger cytostatic effect on MCF-7 compared with that without $\mathrm{HA}$.

\subsection{Synergistic effect}

Table 1

Evaluation of combined index $(\mathrm{Cl})$ at $\mathrm{IC}_{50}(\mathrm{ABE})$ in $\mathrm{CaP} / \mathrm{ABE}-\mathrm{VES}$ and $\mathrm{HA} / \mathrm{CaP} / \mathrm{ABE}-$ VES system

\begin{tabular}{|lllllll|}
\hline Drug/Combo( $\mu \mathrm{M})$ & ABE & VES & PM-CaP & Co-CaP & PM-HA & Co-HA \\
\hline IC $_{50(A B E)}$ & 8.106 & $/$ & 9.811 & 4.322 & 9.002 & 3.673 \\
\hline$I_{50(\mathrm{VES})}$ & $/$ & 484.767 & 34.339 & 15.127 & 40.509 & 16.529 \\
\hline Cl value & $/$ & & 1.337 & 0.327 & 0.983 & 0.188 \\
\hline
\end{tabular}

Combination index $(\mathrm{Cl})$ value was calculated using CompuSyn software. The curve of log $(\mathrm{Cl})$ value and drug effect level $(\mathrm{Fa})$ can clearly show the characteristics and extent of drug interaction[34]. Log (Cl) values of $>0,0$, and $<0$ mean antagonism, superimposition, and synergy, respectively[35]. In this study, the $\mathrm{Cl}$ values of (PM) and CaP/ABE-VES on MCF-7 cell were compared. The $\mathrm{Cl}$ value of HA/CaP/ABE-VES is 0.188 , which has a stronger synergy $(++++)$ and is lower than that of CaP/ABE-VES $(\mathrm{Cl}=0.327)$. In the $\mathrm{CaP} / \mathrm{ABE}-\mathrm{VES}$ and HA/CaP/ABE-VES group, all the log $(\mathrm{Cl})$ values in each corresponding Fa value are lower than $\log (\mathrm{Cl})=0$. The mixed cocktails almost exceed $\log (\mathrm{Cl})=0$. These results indicate that the synergistic effect of HA/CaP/ABE-VES and CaP/ABE-VES on MCF-7 cells is more remarkable than that of 
the cocktail mixture. In addition, $\mathrm{HA} / \mathrm{CaP} / \mathrm{ABE}-\mathrm{VES}$ presents a more remarkable synergistic anti-tumor effect than CaP/ABE-VES because of HA modification.

\section{Conclusion}

In this study, a pH-sensitive dual-drug-loaded nanocomposite material was prepared. HA/CaP/ABE-VES can effectively control the release of $A B E$ and VES in acidic tumor environment. Notably, the incorporation of HA greatly reduced the release of dual drug under normal tissue environment $(\mathrm{pH} \mathrm{7.4),} \mathrm{which} \mathrm{solves}$ the problem of increased drug release caused by the high powderization of CaP. Moreover, even HA/CaP concentrations as high as $200 \mu \mathrm{g} / \mathrm{mL}$ hardly affected the viability of normal cell; thus, $\mathrm{HA} / \mathrm{CaP}$ has excellent in vitro biocompatibility. In addition, the presence of the HA layer greatly reduced the release of drugs in normal cell; therefore, making $\mathrm{HA} / \mathrm{CaP}$ show weaker lethality to normal cell but maintains toxicity to cancer cell. That is why HA/CaP/ABE-VES exhibits a stronger synergistic effect than CaP/ABEVES. The inorganic/organic composite material has better tumor selectivity and is more suitable for antitumor drug delivery. This research established a new drug delivery strategy for breast cancer and provides a new treatment choice (i.e., $\mathrm{ABE}$ ) for tumor treatment.

\section{Declarations}

\section{Credit author statement}

Yuanyuan Liu participated in investigating and writing-original draft. Hui Li participated in conceptualization. Qiaomei Sun supervised the study. Na Gan was responsible for methodology. Shuangshuang Zhang participated in data curation. Xin Wei was in charge of formal analysis. Xiuyun Ren and Xi Xiang performed experiments for revision.

\section{Conflicts of interest}

There are no conflicts to declare.

\section{Acknowledgment}

We appreciate Hui Wang for helping with SEM characterization from the Analytical \& Testing Center of Sichuan University.

\section{References}

1. Johnston S, Martin M, Di Leo A, et al (2019) MONARCH 3 final PFS: a randomized study of abemaciclib as initial therapy for advanced breast cancer. NPJ breast cancer 5:5. DOI: 10.1038/s41523-018-0097-z.

2. Dickler MN, Tolaney SM, Rugo HS, et al (2017) MONARCH 1, A Phase II Study of Abemaciclib, a CDK4 and CDK6 Inhibitor, as a Single Agent, in Patients with Refractory HR+/HER2- Metastatic 
Breast Cancer. Clin Cancer Res 17(23): 5218-5224. DOI: 10.1158/1078-0432.CCR-17-0754.

3. Taniguchi K, Karin M (2018) NF-KB, inflammation, immunity and cancer: coming of age. Nature reviews. Immunology 121:556-571. DOI: 10.1016/j.ijbiomac.2018.10.049.

4. Klein ME, Kovatcheva M, Davis LE, Tap WD, Koff A (2018) CDK4/6 Inhibitors: The Mechanism of Action May Not Be as Simple as Once Thought. Cancer cell 1(34):9-20. DOI:

10.1016/j.ccell.2018.03.023.

5. Jiang Q (2017) Natural Forms of Vitamin E as Effective Agents for Cancer Prevention and Therapy. Adv Nutr 6(8):850-867. DOI: 10.3945/an.117.016329.

6. Hou L, Tian C, Chen D, Yuan Y, Yan Y, Huang Q, Zhang H, Zhang Z (2019) Investigation on vitamin e succinate based intelligent hyaluronic acid micelles for overcoming drug resistance and enhancing anticancer efficacy. Eur J Pharm SCls 140:105071. Doi:10.1016/j.ejps.2019.105071

7. Huang P, Ao J, Zhou L, Su Y, Huang W, Zhu X, Yan D (2016) Facile Approach To Construct Ternary Cocktail Nanoparticles for Cancer Combination Therapy. Bioconjugate chem 7(27):1564-1568. DOI: 10.1021/acs.bioconjchem.6b00158.

8. Chou T-C (2010) Drug combination studies and their synergy quantification using the Chou-Talalay method. Cancer Res 2(70):440-446. DOI: 10.1158/0008-5472.CAN-09-1947.

9. D'Mello SR, Cruz CN, Chen M-L, Kapoor M, Lee SL, Tyner KM (2017) The evolving landscape of drug products containing nanomaterials in the United States. Nat Nanotechnol 6(12):523-529. DOI: 10.1038/nnano.2017.67.

10. Min Y, Caster JM, Eblan MJ, Wang AZ (2015) Clinical Translation of Nanomedicine. Chem Rev 19(115):11147-11190. DOI: 10.1021/acs.chemrev.5b00116.

11. Raafat, A.I., Kamal, H., Sharada, H.M. et al. (2020) Radiation Synthesis of Magnesium Doped Nano Hydroxyapatite/(Acacia-Gelatin) Scaffold for Bone Tissue Regeneration: In Vitro Drug Release Study. J Inorg Organomet Polym 30, 2890-2906. DOI: 10.1007/s10904-019-01418-3

12. Kaczmarek, M, Jurczyk, K, Koper, J K, Paszel-Jaworska, A, Jurczyk, M U (2016) In vitro biocompatibility of anodized titanium with deposited silver nanodendrites. J Mater Sci 51(11), 52595270.DOI: 10.1007/s10853-016-9829-3

13. Huang G, Huang H (2018) Hyaluronic acid-based biopharmaceutical delivery and tumor-targeted drug delivery system. J Control Release 278:122-126. DOI: 10.1016/j.jconrel.2018.04.015.

14. Ravar F, Saadat E, Gholami M, Dehghankelishadi P, Mahdavi M, Azami S, Dorkoosh FA (2016) Hyaluronic acid-coated liposomes for targeted delivery of paclitaxel, in-vitro characterization and invivo evaluation. J Control Release 229:10-22. DOI: 10.1016/j.jconrel.2016.03.012.

15. Xiong H, Du S, Ni J, Zhou J, Yao J (2016) Mitochondria and nuclei dual-targeted heterogeneous hydroxyapatite nanoparticles for enhancing therapeutic efficacy of doxorubicin. Biomaterials 94 : 70-83. DOI: 10.1016/j.biomaterials.2016.04.004.

16. Lee MS, Lee JE, Byun E, Kim NW, Lee K, Lee H, Sim SJ, Lee DS, Jeong JH (2014) Target-specific delivery of siRNA by stabilized calcium phosphate nanoparticles using dopa-hyaluronic acid conjugate. J Control Release 192:122-130. DOI: 10.1016/j.jconrel.2014.06.049. 
17. Ridi F, Meazzini I, Castroflorio B, Bonini M, Berti D, Baglioni P (2017) Functional calcium phosphate composites in nanomedicine. Adv Colloid Interfac 244:281-295. DOI: 10.1016/j.cis.2016.03.006.

18. Qi C, Lin J, Fu L-H, Huang P (2018) Calcium-based biomaterials for diagnosis, treatment, and theranostics. Chem Soc Rev 2(47): 357-403. DOI: 10.1039/c6cs00746e.

19. Lin K, Wu C, Chang J (2014) Advances in synthesis of calcium phosphate crystals with controlled size and shape. Acta Biomater 10(10):4071-4102. DOI: 10.1016/j.actbio.2014.06.017.

20. Guo X, Yan H, Zhao S, Li Z, Li Y, Liang X (2013) Effect of calcining temperature on particle size of hydroxyapatite synthesized by solid-state reaction at room temperature. Adv Powder Techno 6(24):1034-1038. DOI: 10.1016/j.apt.2013.03.002.

21. Kapri S, Maiti S, Bhattacharyya S (2016) Lemon grass derived porous carbon nanospheres functionalized for controlled and targeted drug delivery. Carbon 100:223-235. DOI: 10.1016/j.carbon.2016.01.017.

22. Bastakoti B-P, Inuoe M, Yusa S-i, Liao S-H, Wu KC-W, Nakashima K, Yamauchi Y (2012) A block copolymer micelle template for synthesis of hollow calcium phosphate nanospheres with excellent biocompatibility. Chem Commun 52(48):6532-6534. DOI: 10.1039/c2cc32279j.

23. Liu T-Y, Chen S-Y, Liu D-M, Liou S-C (2005) On the study of BSA-loaded calcium-deficient hydroxyapatite nano-carriers for controlled drug delivery. J Control Release 1(107):112-121. DOI: 10.1016/j.jconrel.2005.05.025.

24. Matsumoto T, Okazaki M, Inoue M, Yamaguchi S, Kusunose T, Toyonaga T, Hamada Y, Takahashi J (2004) Hydroxyapatite particles as a controlled release carrier of protein. Biomaterials 17(25): 38073812. DOI: 10.1016/j.biomaterials.2003.10.081.

25. Oonishi H, Hench LL, Wilson J, Sugihara F, Tsuji E, Kushitani S, Iwaki H (1999) Comparative bone growth behavior in granules of bioceramic materials of various sizes. J. Biomed Mater Res 1(44):31-43. DOI: 10.1002/(sici)1097-4636(199901)44:1<31::aid-jbm4>3.0.co;2-9.

26. Xie Y, Liu Y, Wang Y, Wang S, Jiang T (2012) Chitosan matrix with three dimensionally ordered macroporous structure for nimodipine release. Carbohyd Polym 4(90):1648-1655. DOI: 10.1016/j.carbpol.2012.07.045.

27. Li W-M, Chen S-Y, Liu D-M (2013) In situ doxorubicin-CaP shell formation on amphiphilic gelatin-iron oxide core as a multifunctional drug delivery system with improved cytocompatibility, $\mathrm{pH}$-responsive drug release and MR imaging. Acta biomaterialia. 2(9):5360-5368. DOI:

10.1016/j.actbio.2012.09.023.

28. Ding G-J, Zhu Y-J, Qi C, Lu B-Q, Chen F, Wu J (2015) Porous hollow microspheres of amorphous calcium phosphate: soybean lecithin templated microwave-assisted hydrothermal synthesis and application in drug delivery. J Mater Chem B 9(3):1823-1830. DOI: 10.1039/c4tb01862a.

29. Han S-Y, Han HS, Lee SC, Kang YM, Kim I-S, Park JH (2011) Mineralized hyaluronic acid nanoparticles as a robust drug carrier. J Mater Chem 22(21):7996. DOI: 10.1039/c1jm10466g.

30. Zhu, Wei Bo; Chen, Jia; Yan, Tin Ting; Chen, Qing Hua (2013) Effect of Konjac Glucomannan Content on the Structure and Properties of Sodium Hyaluronate/Chitosan/Konjac Glucomannan Composite 
Films. AMR 738:67-72. DOI: 10.4028/www.scientific.net/AMR.738.67.

31. Liang Y-H, Liu C-H, Liao S-H, Lin Y-Y, Tang H-W, Liu S-Y, Lai I-R, Wu KC-W (2012) Cosynthesis of cargoloaded hydroxyapatite/alginate core-shell nanoparticles (HAP@Alg) as pH-responsive nanovehicles by a pre-gel method. ACS Appl Mater Inter 12(4): 6720-6727. DOI: 10.1021/am301895u.

32. Orrenius S, Zhivotovsky B, Nicotera P (2003) Regulation of cell death: the calcium-apoptosis link. Nat Rev 7(4):552-565. DOI: 10.1038/nrm1150.

33. Zingg J-M, Azzi A, Meydani M (2017) a-Tocopheryl Phosphate Induces VEGF Expression via CD36/PI3Ky in THP-1 Monocytes. J Cell Biochem 7(118):1855-1867. DOI: 10.1002/jcb.25871.

34. Chou T-C (2006) Theoretical basis, experimental design, and computerized simulation of synergism and antagonism in drug combination studies. Pharmacol Rev 3(58): 621-681. DOI: 10.1124/pr.58.3.10.

35. Qiu C, Wei W, Sun J, Zhang H-T, Ding J-S, Wang J-C, Zhang Q (2016) Systemic delivery of siRNA by hyaluronan-functionalized calcium phosphate nanoparticles for tumor-targeted therapy. Nanoscale 26(8):13033-13044. DOI: 10.1039/c6nr04034a.

\section{Figures}

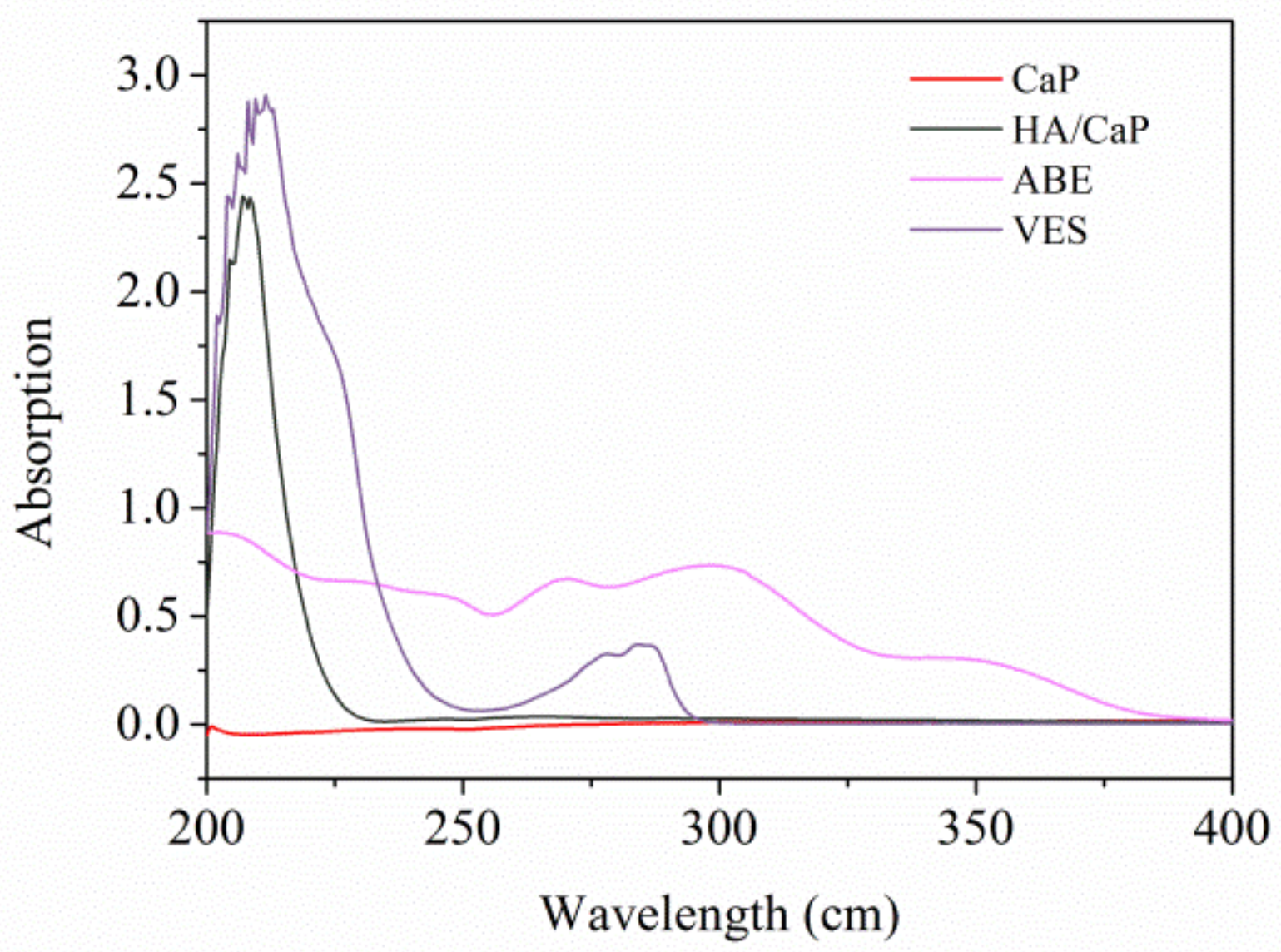

Figure 1 
Ultraviolet spectra of $\mathrm{ABE}, \mathrm{VES}, \mathrm{CaP}$ and $\mathrm{HA} / \mathrm{CaP}$
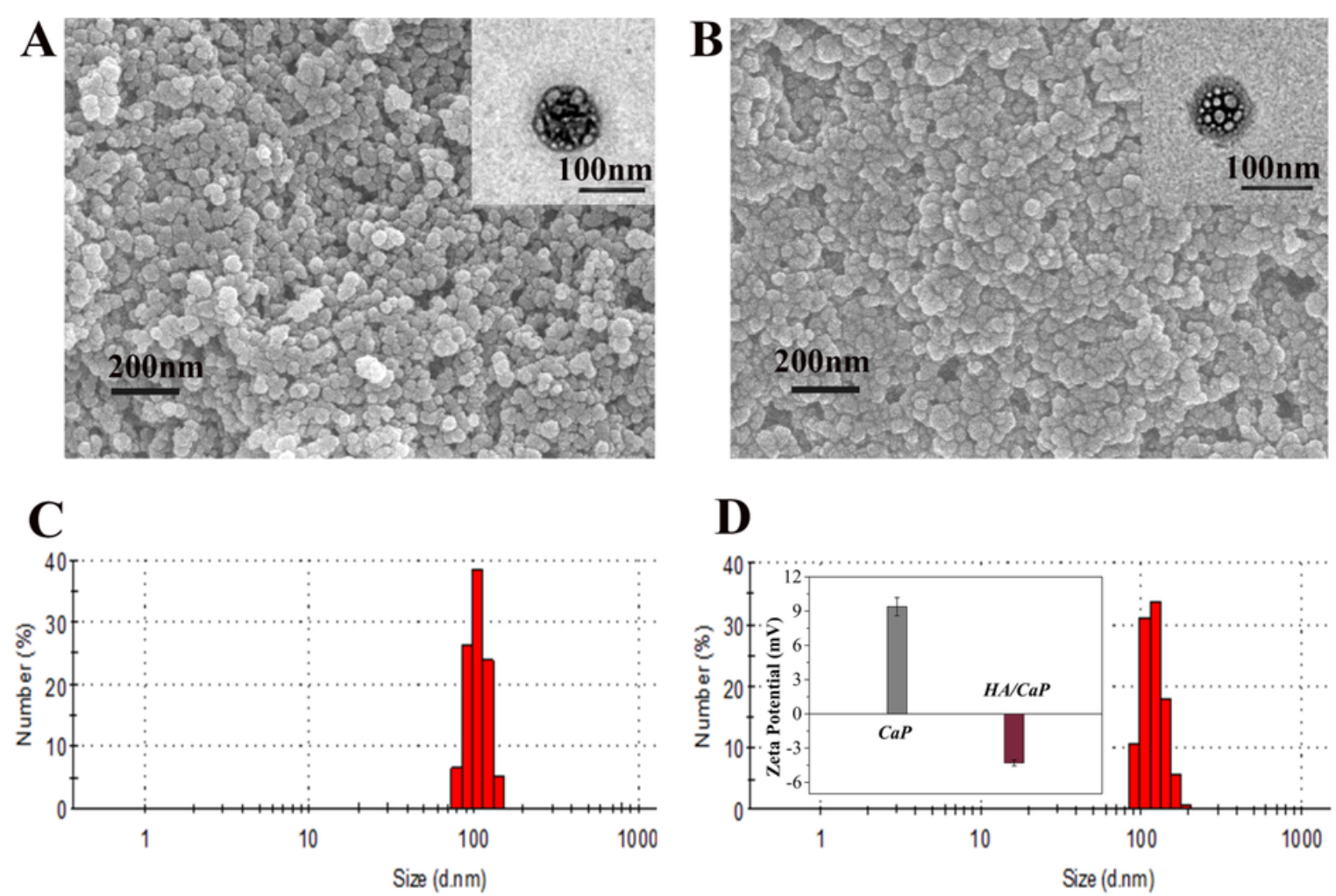

Figure 2

SEM image and TEM partial magnification of $\mathrm{CaP}(\mathrm{A})$ and $\mathrm{HA} / \mathrm{CaP}(\mathrm{B})$; DLS particle size distribution of $\mathrm{CaP}(\mathrm{C})$ and $\mathrm{HA} / \mathrm{CaP}(\mathrm{D})$; Zeta potential diagram (D) 
A

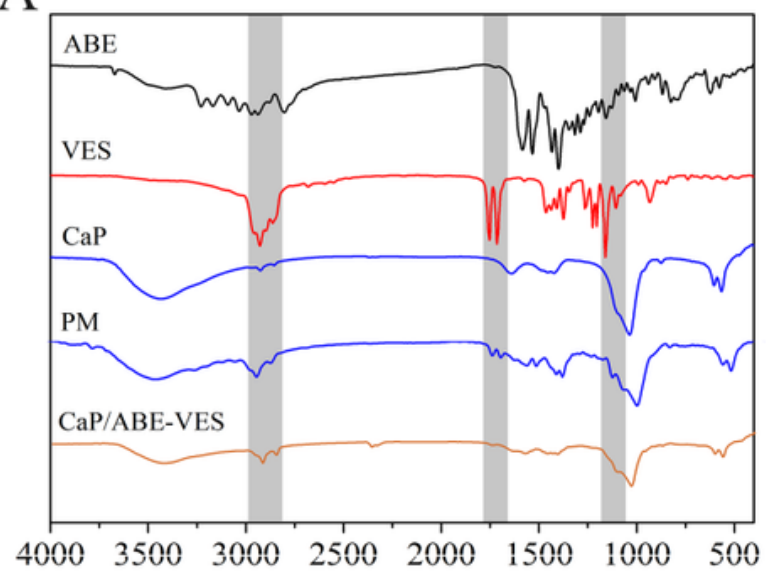

$\mathrm{C}$

C Wavenumber $\left(\mathrm{cm}^{-1}\right)$

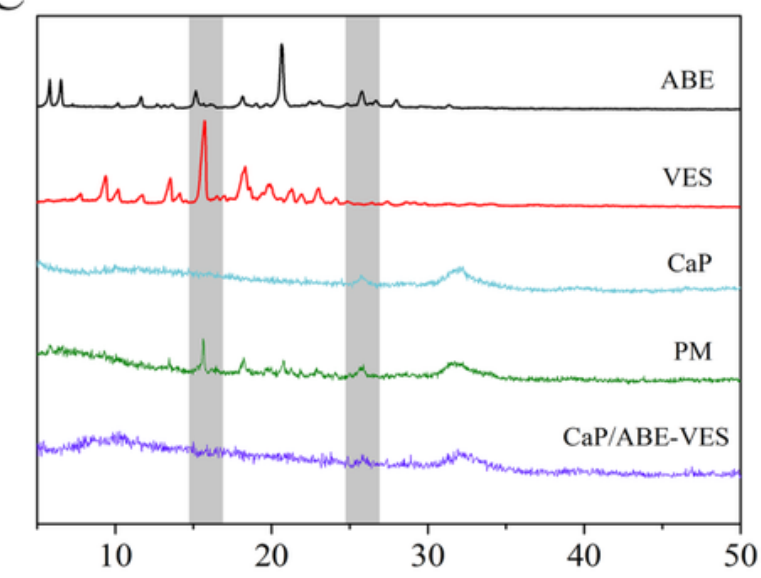

$\mathrm{E}$

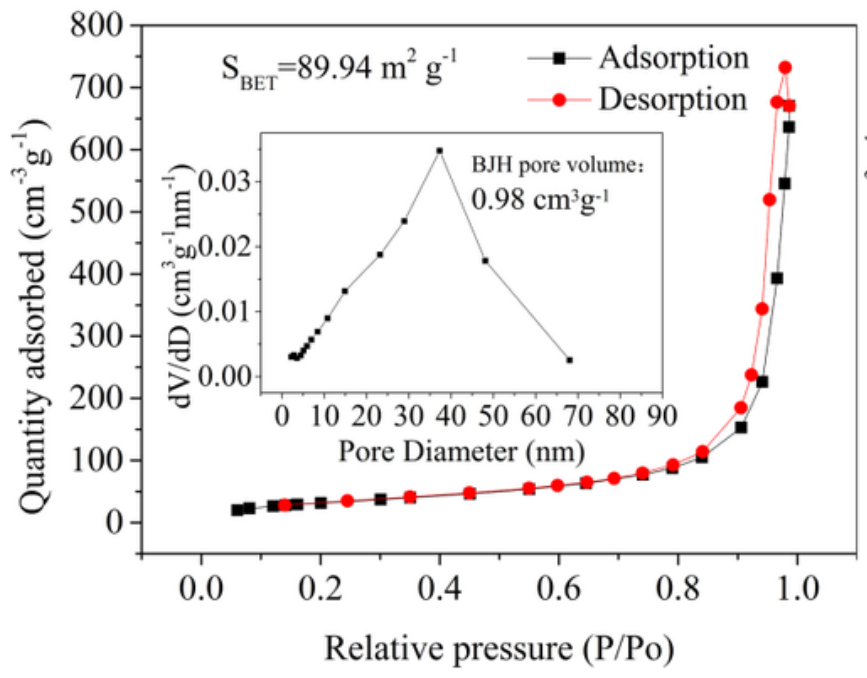

$\mathrm{B}$

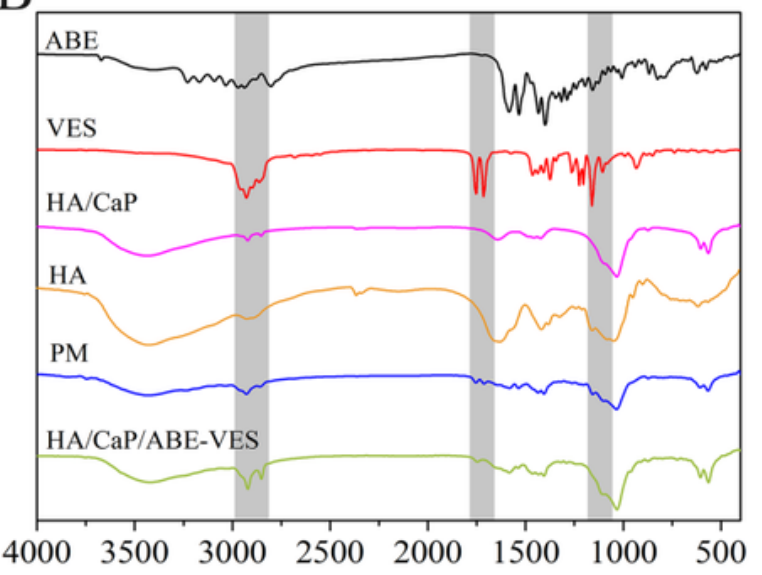

$\mathrm{D}$

Wavenumber $\left(\mathrm{cm}^{-1}\right)$

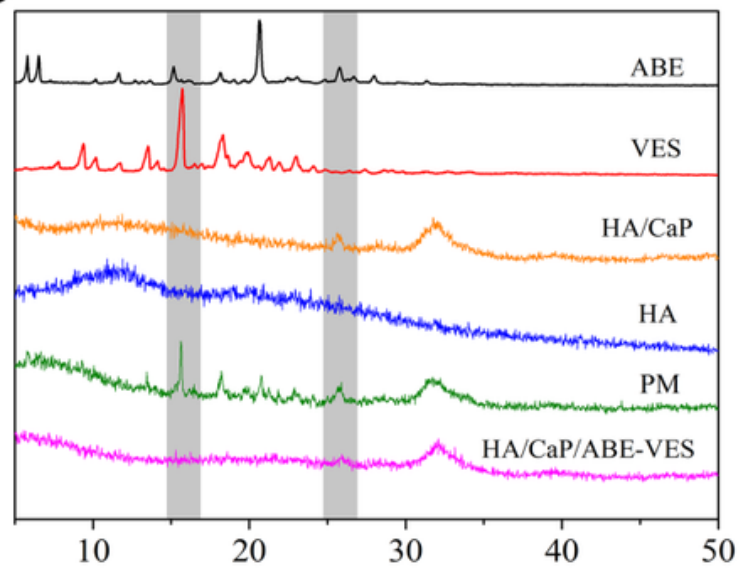

$2 \theta /{ }^{\circ}$

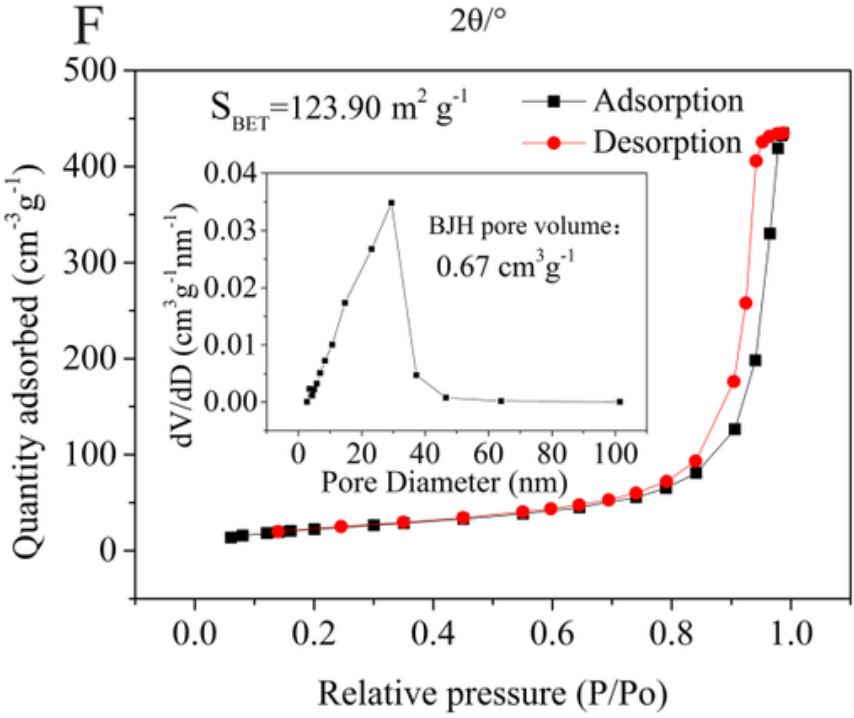

\section{Figure 3}

Infrared spectra (A, B); XRD patterns (C, D); N2 adsorption-desorption isotherm and BJH desorption pore size distribution curve of $\mathrm{CaP}(\mathrm{E})$ and $\mathrm{HA} / \mathrm{CaP}(\mathrm{F})$ 

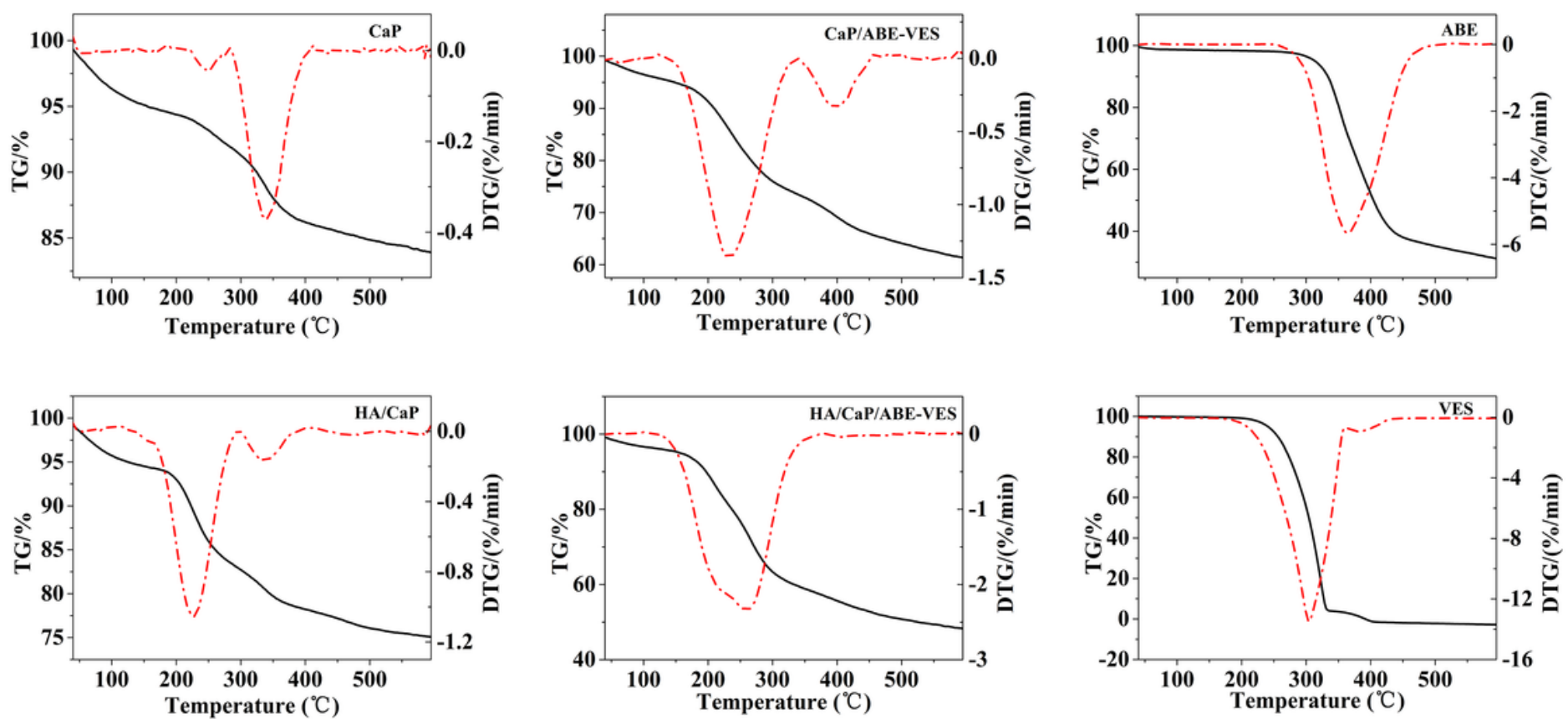

Figure 4

TG curves of single drug; blank and drug-loaded materials 

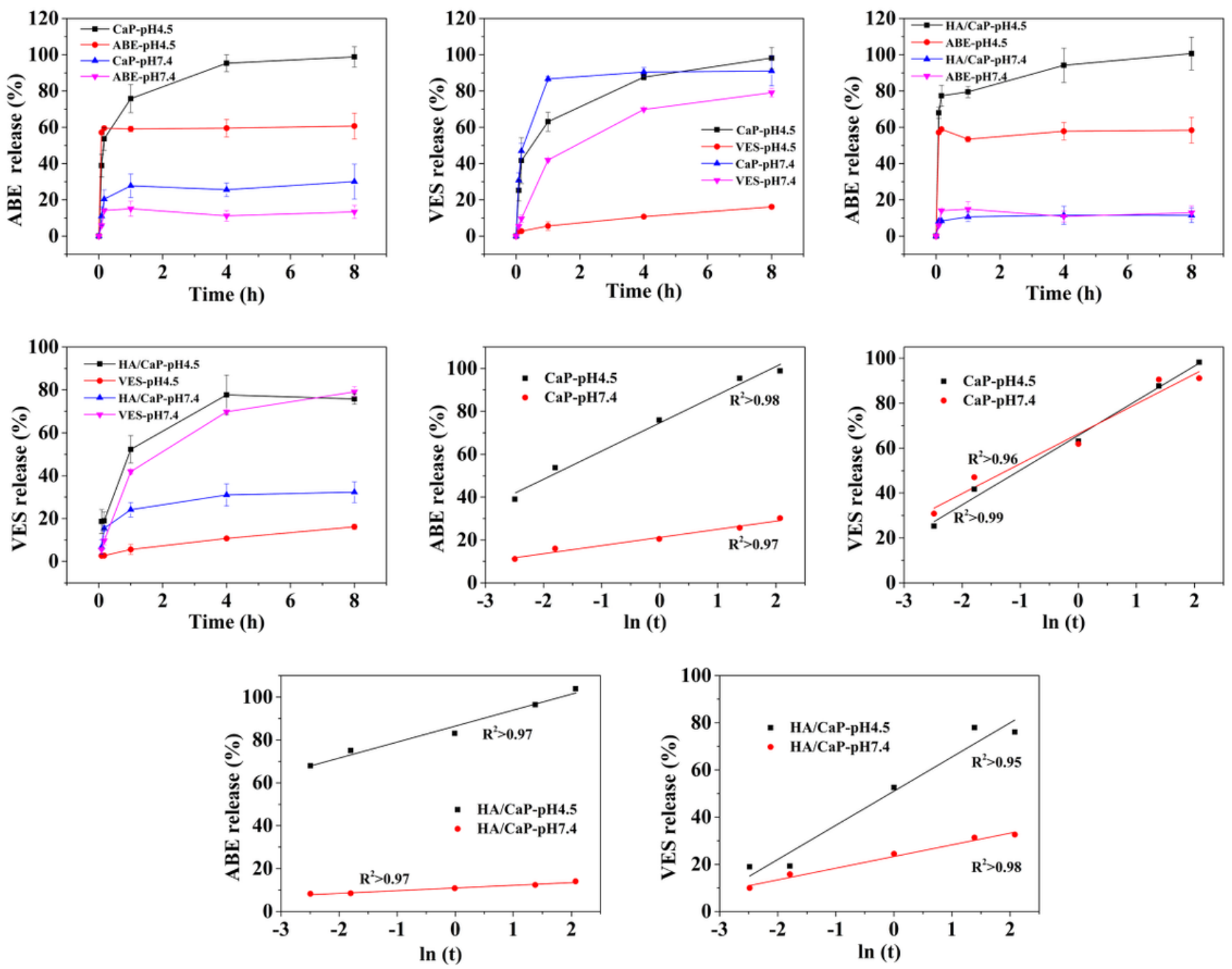

Figure 5

In vitro drug release curves; cumulative release percentage versus natural logarithm of time plot for drugloaded system 

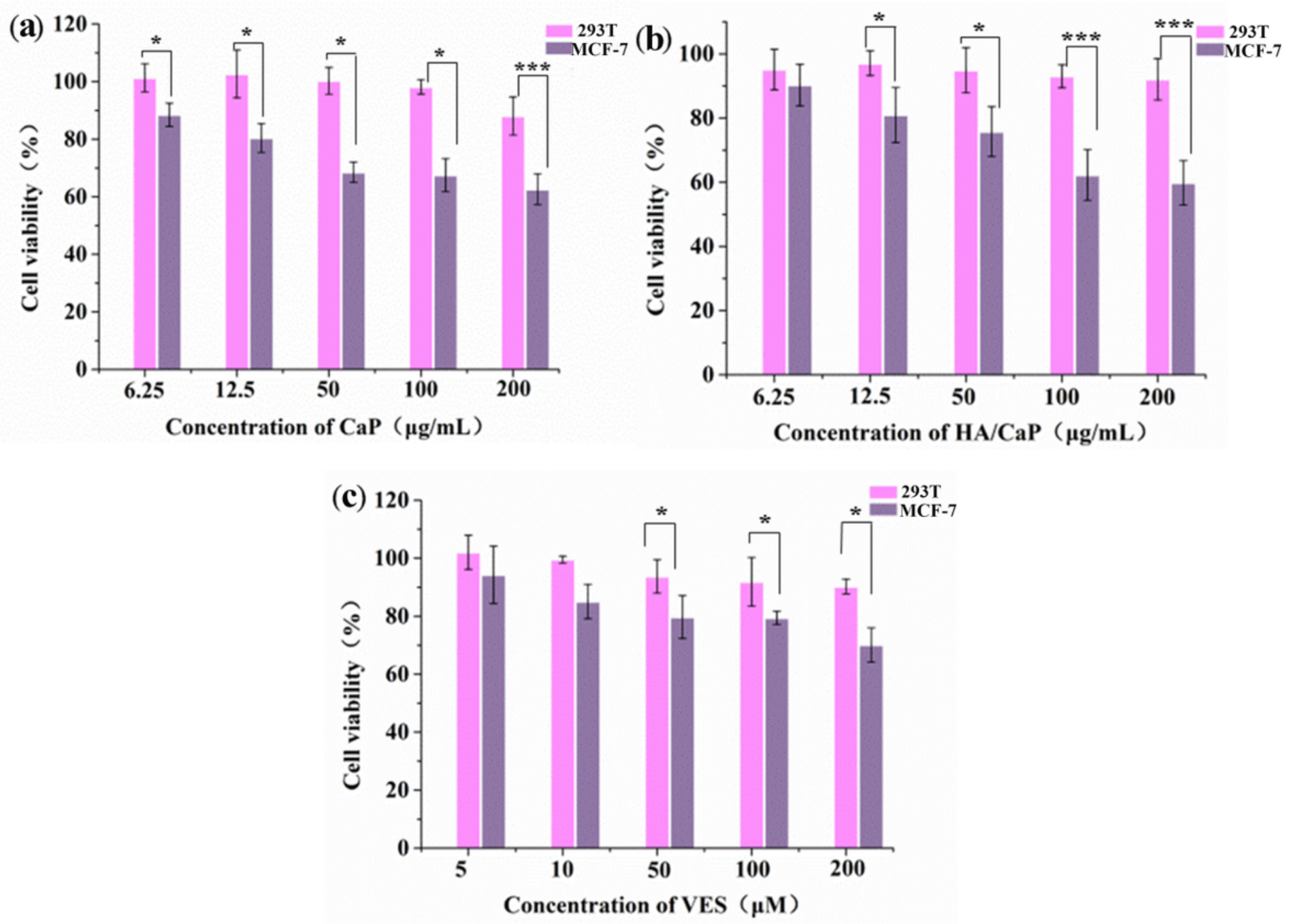

Figure 6

Cytotoxicity of CaP (a) HA/CaP (b) and VES (c) 

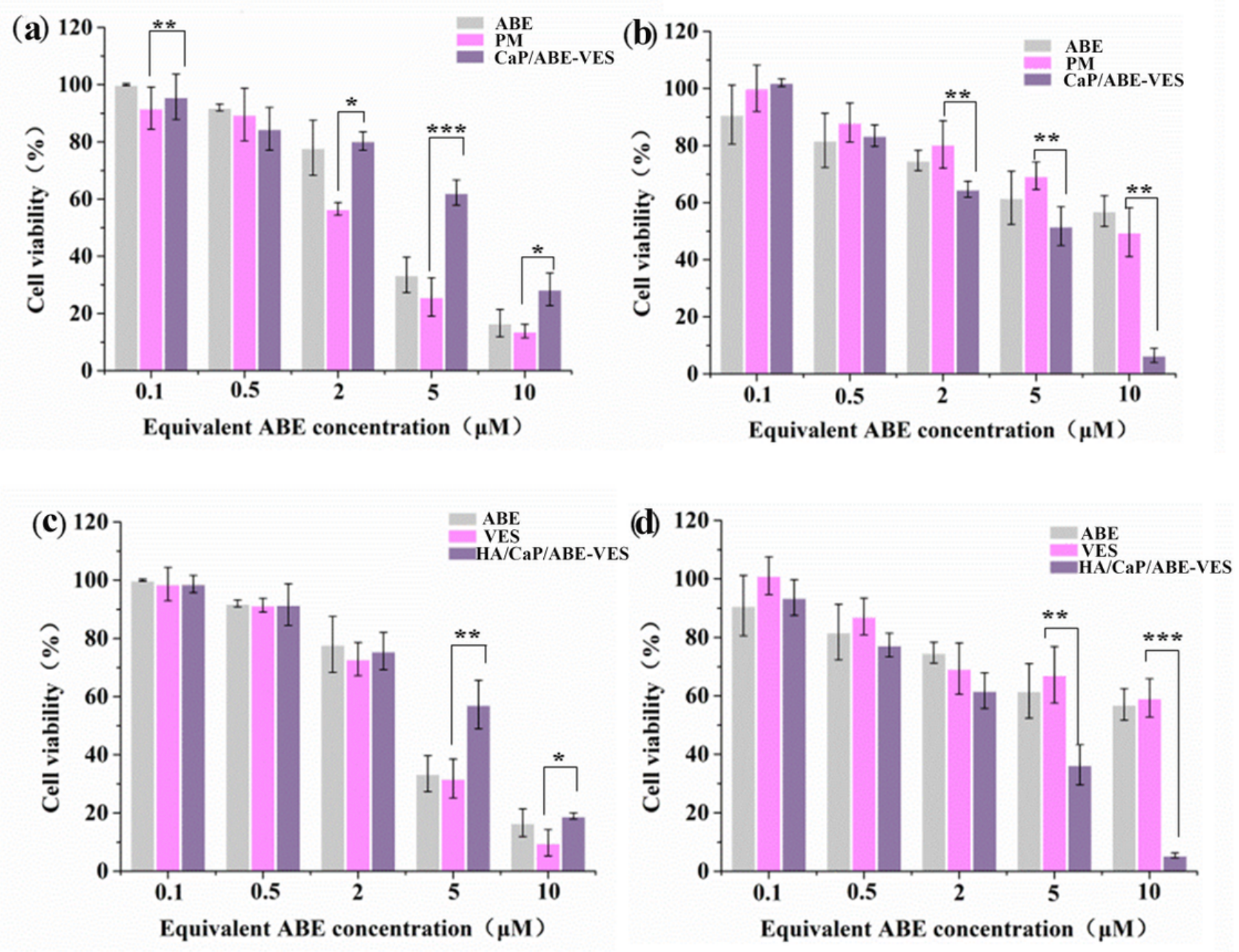

Figure 7

Cell viability of CaP/ABE-VES, HA/CaP/ABE-VES, PM in 293T cells (a, c), and MCF-7 cells(b, d) 


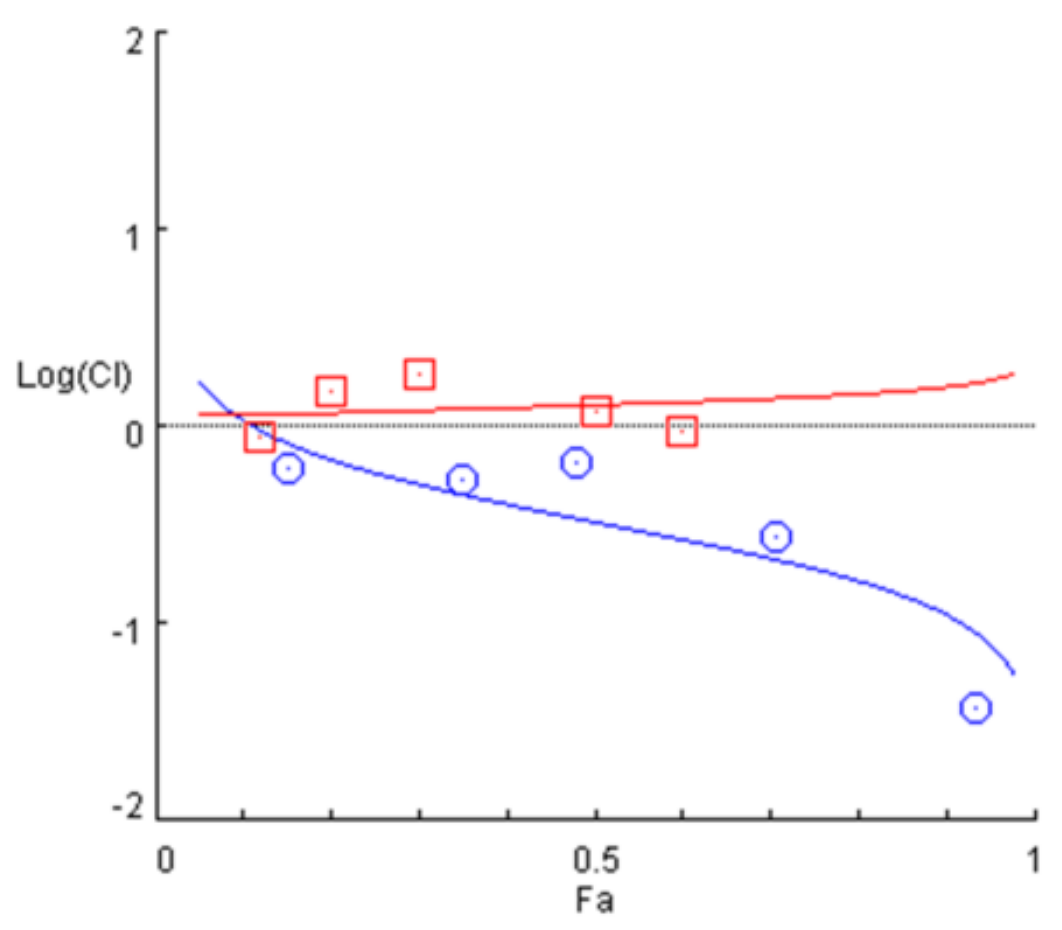

\begin{tabular}{|ll|}
\hline & co-CaP \\
$\square$ & PM \\
\hline
\end{tabular}

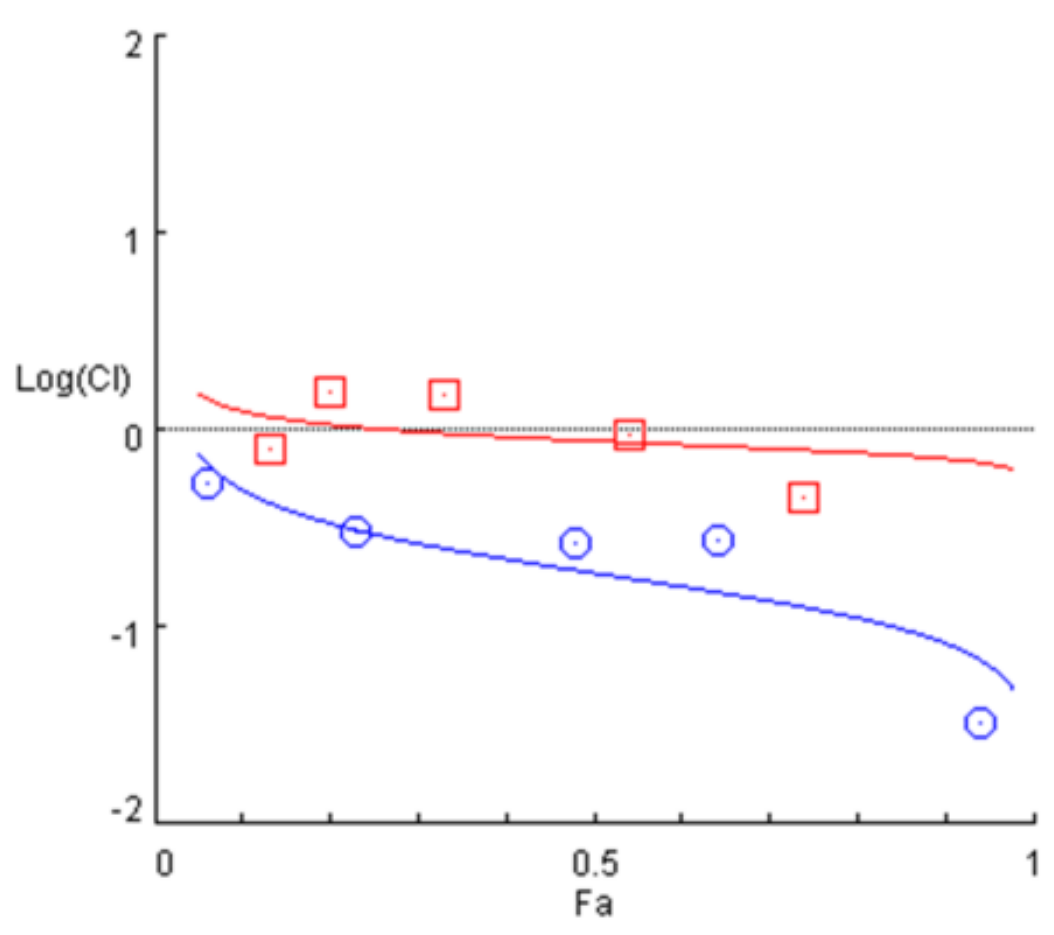

\section{Figure 8}

Fa-Log (Cl) Plot of CaP/ABE-VES(co-CaP) and HA/CaP/ABE-VES(co-HA)

\section{Supplementary Files}

This is a list of supplementary files associated with this preprint. Click to download. 
- Supplementarymaterial.docx

Page 21/21 